\title{
STRATEGY FOR RESUMING ELECTIVE SURGICAL PROCEDURES DURING \& AFTER COVID-19 PANDEMIC
}

Shabir Ahmed Lehria, Muhammad Iqbal Khan ${ }^{b}$, Riffat Arbabc

aProfessor of Neurosurgery/ Dean Post Graduate Medical Institute Quetta.

${ }^{b}$ Assistant Professor of Surgery/ Deputy Registrar Post Graduate Medical Institute Quetta.

'Assistant Professor of Surgery, Bolan Medical College Quetta.

\section{ABSTRACT:}

COVID-19 pandemic has afflicted the individuals, national economies, and healthcare system worldwide. It has badly struck the ongoing and planned surgical procedures in nearly all healthcare centers which has led the surgical procedures to come to a grinding halt. This serious issue invites comments from surgical experts throughout the world.

KEYWORDS: Elective Surgeries, COVID-19, Operating Room (OR).

\section{How to cite this:}

doi: https://doi.org/10.37723/jumdc.v12i2.529

Lehri SA, Khan MI, Arbab R. STRATEGY FOR RESUMING ELECTIVE SURGICAL PROCEDURES DURING \& AFTER COVID-19 PANDEMIC. jumdc. 2021;12(2):76-79.

doi: https://doi.org/10.37723/jumdc.v12i2.529

This is an Open Access article distributed under the terms of the Creative Commons Attribution License (http://creativecommons.org/licenses/by/4.0), which permits unrestricted use, distribution, and reproduction in any medium provided the original work is properly cited.

COVID-19 has affected more than 5.3 million people throughout the world with almost more than 342000 deaths $^{[1]}$. This is not static and is growing day by day, in Pakistan, more than 4 Lac people are infected with 10000 deaths. In Balochistan, it has been estimated that more than $90 \%$ of the population has now contracted the virus ${ }^{[2]}$. This lethal virus has badly hit the socio-economic status of many countries throughout the world [3], casting precious lives of healthcare professionals in many countries, including Pakistan, and health care professionals are labeled as national heroes throughout the world[4].

The COVID-19 pandemic has seriously affected the healthcare system globally, leading to a shortage of resources, redeployment of healthcare providers at different stations, allocation of anesthesiologists and surgical ICU's to aid the ongoing medical crisis. This has a serious impact on future elective surgeries. In many countries, the whole surgical procedure has been stopped ${ }^{[5]}$. This is now a global challenge to restart elective surgeries, and as Benjamin Franklin said, "By failing to prepare, you are preparing to fail" means this is high time to strategize accordingly. This makes an essential burden on the shoulder of surgical experts to formulate a comprehensive course of action nationally 
to restart the elective surgical procedures. Normally, surgeons focused on their knowledge based on transmission of hepatitis B, C, and HIV, referring to them as universal precautions, but the COVID-19 crisis has taken the surgeons to the next level of personal protective equipment (PPE) $)^{[6,7]}$.

There has been no proper studies linked to COVID-19 transmission through surgical smoke, CO2 leakage from pnemoperitonium, still initially Laparoscopic Surgeries were discouraged, but the advantages of minimum invasive surgeries should not be sacrificed, and the potential risk of COVID-19 should be minimized based on patient, surgical team, anesthesia team, hospital management and Operating room (OR) team dimensions $[8,9,10,11$,$] .$

Aside from precautions and care, the most important step should be "Urgency of Surgery." Surgical Problems requiring urgent interventions should be prioritized first. Cases which are nonlife-threatening should be deferred or delayed. These decisions are to be made based on the nature of surgical disease, availability of resources like surgeons, anesthesiologists, nurses, availability of ventilators, supply of oxygen, PPE's, Blood products and ICU's etc ${ }^{[12,13]}$. Based on guidelines from apex organizations, a hospital review committee should be constituted, which should help the surgeons in taking decisions for surgical procedures.
Corresponding Author:

Dr. Muhammad Iqbal,

Assistant Professor of Surgery/ Deputy

Registrar Post Graduate Medical Institute

Quetta.

Email:miqbaljaffar@yahoo.com

The same issue of surgical procedure's urgency and resources have been discussed worldwide, and different guidelines and the scoring system have been deviced. Recently, a Medically Necessary Time-Sensitive (MeNTS) scoring system has been published, which incorporates resources, limitations, and COVID-19 transmission risk to health care providers and patients. This scoring system can be an effective tool at every tertiary and secondary health care center $[14,15,16,17]$.

On the other hand, where a surgical patient is received who is COVID-19 positive, it is recommended that surgery should be deferred until he is asymptomatic for three days and have two negative results 24 hours apart. It is also recommended that every patient undergoing surgery should be tested for COVID-19. This is because if an asymptomatic patient is operated on and after that, he comes in contact with a healthy but immune-compromised patient or healthcare provider, it may lead to severe morbidity and mortality of the later ${ }^{[18,19]}$, so in this state of a pandemic it is more acceptable to avoid surgical procedures which are non-essential because it will not only prevent exposure to viral

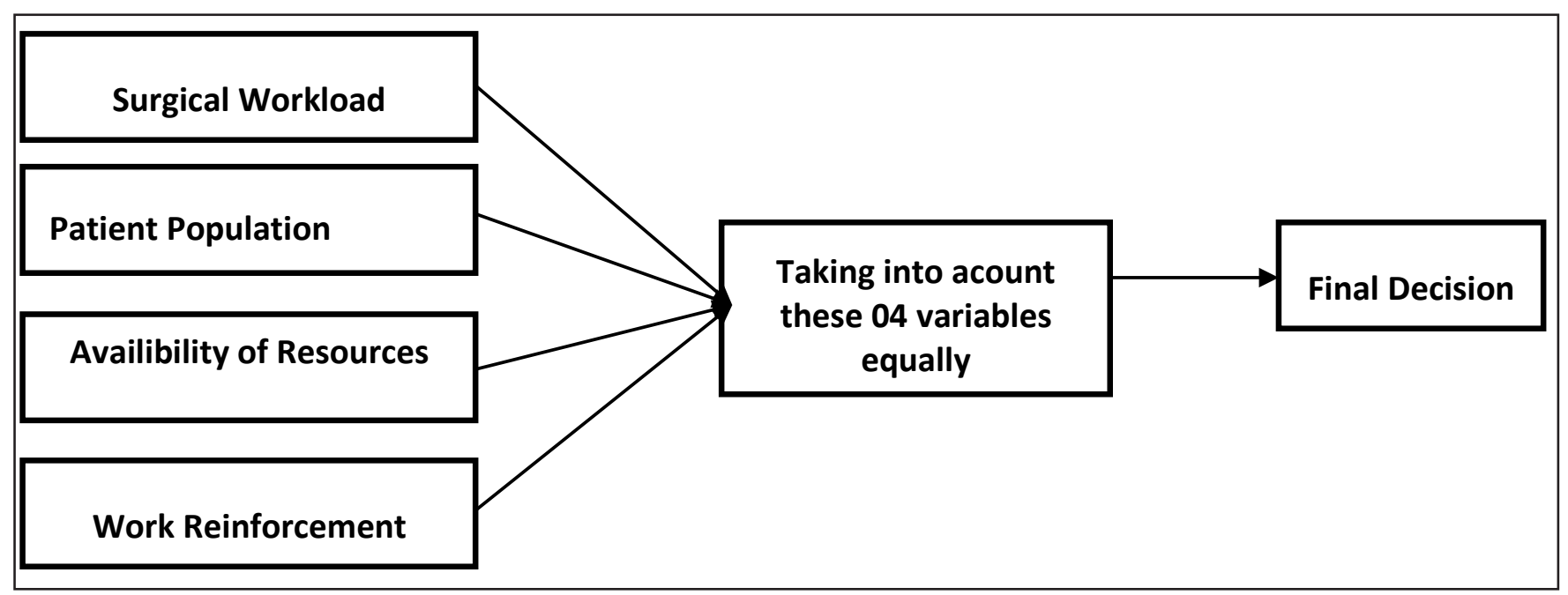

Figure-I. Essential variables to plan elective surgeries during \& after COVID-19 pandemic. 
load but will also preserve human resource and other health care resources ${ }^{[7]}$.

Worldwide, surgeons are worried about pending surgical workload and strategy for resuming elective lists. It is advised that comprehensive checklists should be formulated locally or in accordance with apex organizations to resume surgeries. But these checklists should essentially include surgical workload, patient population, hospital capacity, and availability of resources along with work reinforcement in case of any change in the scenario, as shown in Figure-I $[19,20]$.

The world is now moving to develop herd immunity alongwith efforts to make an effective vaccine, surgeons are always being considered as fearless warrior who are ready to take challenges, but this time it's the need of hours to make a comprehensive plan for this major surgical issue of pending cases. This comprehensive plan should effectively address protective protocols in view of our resources.

ACKNOWLEDGMENT: Imran Khan Zarkoon, Relief Commissioner cum Director General Provincial Disaster Management Authority Balochistan.

CONFLICT OF INTEREST: All authors disclose no conflict of interest.

\section{$\begin{array}{llll}\text { GRANT } & \text { SUPPORT } & \& & \text { FINANCIAL }\end{array}$ DISCLOSURE: None}

\section{REFERENCES:}

1. COVID-19 Dashboard by the Centre for Systems Science and Engineering at Johns Hopkins University; 2020 [cited 2020 May 23]. Available from: https:// coronavirus.jhu. edu/map.html.

2. NDMA National Disaster Management Authority Pakistan. 2020 [cited 2020 December 28]. Available from: http://web. ndma.gov.pk/ Accessed on December 28, 2020.

3. Tandon PN. COVID-19: Impact on health of people and wealth of nations. Indian Journal of Medical Research. 2020;151(2):121-123.
DOI: 10.4103/ijmr.IJMR_664_20

4. Lane T. Dulce et decorum est. Annals Royal College of Surgeon England. 2020;102(5):321-322.

5. Negopdiev D, Collaborative C, Hoste E. Elective surgery cancellations due to the COVID-19 pandemic: global predictive modelling to inform surgical recovery plans. British Journal of Surgery. 2020;107(11):1440-1449.

6. Brat GA, Hersey S, Chhabra K, Gupta A, Scott J. Protecting surgical teams during the COVID-19 outbreak: a narrative review and clinical considerations. Annals of Surgery. 2020. Doi: 10.1097/SLA.0000000000003926 PMID: 32379080

7. Intercollegiate general surgery guidance on COVID-19, 2nd Revision. 2020 [cited 2020 7th May]. Available from: https:// news.rcpsg.ac.uk/news/updated-generalsurgery-guidance-on-covid-19-2ndrevision7-april-2020/.

8. SAGES and EAES recommendations regarding surgical response to COVID-19 crisis. 2020 [cited 2020 March 29]. Available from https://www.sages.org/recommendationssurgical-response-covid-19/. Accessed on 14th May 2020.

9. Vigneswaran $Y$, Prachand VN, Posner MC, Matthews JB, Hussain $M$. What is the appropriate use of laparoscopy over open procedures in the current COVID-19 climate?. Journal of Gastrointestinal Surgery. 2020;1: 1686-1691. Doi: 10.1007/s11605-02004592-9

10. Mowbray NG, Ansell J, Horwood J, Cornish J, Rizkallah Porker A, et al. Safe management of surgical smoke in the age of COVID-19. The British Journal of Surgery. 2020. Doi: 10.1002/bjs.11679PMID: 32363596

11. Sharma D, Agrawal V, Agarwal P. Roadmap for Restarting Elective Surgery During/ After COVID-19 Pandemic. Indian Journal of Surgery. 2020:1-5. Doi: 10.1007/s12262020-02468-5

12. NHS clinical guide to surgical prioritisation during the corona virus pandemic. 2020 [cited 15 May 2020]. Available from: https://www. england.nhs. uk/coronavirus/wp-content/ uploads/sites/52/2020/03/C0221-specialty- 
guide-surgical-prioritisation-v1.pdf.

13. Argenziano M, Fischkoff $K$, Smith CR. Surgery scheduling in a crisis. New England Journal of Medicine. 2020. Doi: 10.1056/ NEJMc2017424

14. Prachand VN, Milner R, Angelos P, Posner MC, Fung JJ, Agrawal N, et al. Medically-necessary, time-sensitive procedures: a scoring system to ethically and efficiently manage resource scarcity and provider risk during the COVID-19 pandemic. Journal of the American College of Surgeons. 2020: 281-288. Doi: 10.1016/j. jamcollsurg.2020.04.011

15. American College of Surgeons COVID-19: elective case triage guidelines for surgical care. Available from https://www.facs. org/covid-19/clinical-guidance/electivecaseOnline March 24, 2020. Accessed 12th May 2020.

16. NCPS Guide for prioritisation of urgent scheduled surgical conditions. 2020 [cited 2020 May 11].

17. American College of Surgeons; COVID-19 and surgical procedures:a guide for patients. 2020 Online March 31. https://www.facs. org/covid-19/clinical-guidance/patient-guide Downloaded on 14th May 2020.

18. Nahshon C, Bitterman A, Haddad R, Hazzan D, Lavie O. Hazardous postoperative outcomes of unexpected COVID-19 infected patients: a call for global consideration of sampling all asymptomatic patients before surgical treatment. World Journal of Surgery. 2020;44(9): :2477-2481. Doi: 10.1007/ s00268-020-05575-2

19. Tuech JJ, Gangloff A, Schwarz L. Our challenge is to adapt the organization of our system to the six stages of the epidemic to go beyond the COVID-19 crisis. The British Journal of Surgery. 2020;107(7):e189. Doi: 10.1002/ bjs.11639PMID: 32352560

20. Guerci C, Maffioli A, Bondurri AA, Ferrario L, Lazzarin F, Danelli P. COVID-19: How can a department of general surgery survive in a pandemic?. Surgery. 2020;167:909-911. Doi: $10.1016 /$ j.surg.2020.03.012

\section{Author's Contribution:}

Shabir Ahmed Lehri: Writing manuscript and study design, Over all supervision

Muhammad Iqbal Khan: Writing references, Data analysis \& framing of manuscript.

Riffat Arbab: collection of data on previous studies on COVID-19

Submitted for publication:10-12-2020 Accepted after revision: 26-04-2021 